\title{
Systemic Inflammation in Young Adults Is Associated with Abnormal Lung Function in Middle Age
}

\author{
Ravi Kalhan ${ }^{1 *}$, Betty T. Tran ${ }^{2}$, Laura A. Colangelo ${ }^{3}$, Sharon R. Rosenberg ${ }^{1}$, Kiang Liư ${ }^{3}$, Bharat \\ Thyagarajan ${ }^{4}$, David R. Jacobs Jr. ${ }^{5,6}$, Lewis J. Smith'
}

1 Asthma-Chronic Obstructive Pulmonary Disease (COPD) Program, Division of Pulmonary and Critical Care Medicine, Northwestern University Feinberg School of Medicine, Chicago, Illinois, United States of America, 2 Division of Pulmonary and Critical Care, University of Washington, Seattle, Washington, United States of America, 3 Department of Preventive Medicine, Northwestern University Feinberg School of Medicine, Chicago, Illinois, United States of America, 4 Department of Laboratory Medicine and Pathology, University of Minnesota Medical School, Minneapolis, Minnesota, United States of America, 5 Division of Epidemiology and Community Health, University of Minnesota School of Public Health, Minneapolis, Minnesota, United States of America, 6 Department of Nutrition, University of Oslo, Oslo, Norway

\begin{abstract}
Background: Systemic inflammation is associated with reduced lung function in both healthy individuals and those with chronic obstructive pulmonary disease (COPD). Whether systemic inflammation in healthy young adults is associated with future impairment in lung health is uncertain.

Methodology/Principal Findings: We evaluated the association between plasma fibrinogen and C-reactive protein (CRP) in young adults and lung function in the Coronary Artery Risk Development in Young Adults cohort study. Higher year 7 fibrinogen was associated with greater loss of forced vital capacity (FVC) between years 5 and 20 ( $439 \mathrm{~mL}$ in quartile 4 vs. $398 \mathrm{~mL}$ in quartile $1, \mathrm{P}<0.001)$ and forced expiratory volume in 1 second $\left(\mathrm{FEV}_{1}\right)(487 \mathrm{~mL}$ in quartile 4 vs. $446 \mathrm{~mL}$ in quartile $1, \mathrm{P}<0.001$ ) independent of cigarette smoking, body habitus, baseline lung function and demographic factors. Higher year 7 CRP was also associated with both greater loss of FVC ( $455 \mathrm{~mL}$ in quartile 4 vs. $390 \mathrm{~mL}$ in quartile $1, P<0.001)$ and FEV $(491 \mathrm{~mL}$ in quartile 4 vs. $442 \mathrm{~mL}$ in quartile $1, P=0.001)$. Higher year 7 fibrinogen and CRP were associated with abnormal FVC at year 20 (odds ratio (OR) per standard deviation 1.51 (95\% confidence interval $(\mathrm{Cl}): 1.30-1.75)$ for fibrinogen and 1.35

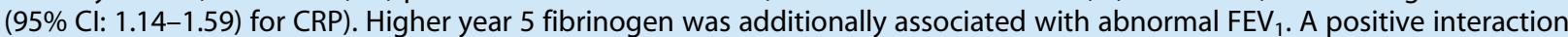
was observed between pack-years cigarette smoking and year 7 CRP for the COPD endpoint, and among participants with greater than 10 pack-years of cigarette exposure, year 7 CRP was associated with greater odds of COPD at year 20 (OR per standard deviation 1.53 (95\% Cl: 1.08-2.16).
\end{abstract}

Conclusion/Significance: Systemic inflammation in young adults is associated with abnormal lung function in middle age. In particular, elevated CRP may identify vulnerability to COPD among individuals who smoke.

Trial Registration: ClinicalTrials.gov NCT00005130

Citation: Kalhan R, Tran BT, Colangelo LA, Rosenberg SR, Liu K, et al. (2010) Systemic Inflammation in Young Adults Is Associated with Abnormal Lung Function in Middle Age. PLoS ONE 5(7): e11431. doi:10.1371/journal.pone.0011431

Editor: Irwin Reiss, Erasmus University Rotterdam, Netherlands

Received January 20, 2010; Accepted June 13, 2010; Published July 2, 2010

Copyright: (c) 2010 Kalhan et al. This is an open-access article distributed under the terms of the Creative Commons Attribution License, which permits unrestricted use, distribution, and reproduction in any medium, provided the original author and source are credited.

Funding: The CARDIA study is funded by National Heart, Lung, and Blood Institute (NHLBI, www.nhlbi.nih.gov) contracts N01-HC-48047, N01-HC-48048, N01-HC 48049, N01-HC-48050 (CARDIA field centers), N01-HC-95095 (CARDIA Coordinating Center), and N01-HC045134 Reading Center (CARDIA Pulmonary Reading Center). NHLBI had no role in the data analysis, interpretation, or writing of this report. This manuscript was reviewed and approved by CARDIA's independent Publications and Presentations and Steering Committees.

Competing Interests: Ravi Kalhan has served as a paid consultant to Boehringer-Ingelheim, Dey Pharmaceuticals, and AstraZeneca, and has received honoraria for speaking on behalf of GlaxoSmithKline, Boehringer-Ingelheim, Pfizer, and AstraZeneca, and is the recipient of research grant support from GlaxoSmithKline. No other authors have competing interests to disclose.

*E-mail: r-kalhan@northwestern.edu

\section{Introduction}

Among both healthy individuals and chronic obstructive pulmonary disease (COPD) patients, an inverse association between blood levels of fibrinogen and C-reactive protein (CRP) and forced expiratory volume in 1 second $\left(\mathrm{FEV}_{1}\right)$ has been reported $[1,2,3,4]$. Recent data indicate that CRP and other inflammation-sensitive proteins may be risk factors for COPD $[5,6]$. However, conflicting information exists regarding the relationship between systemic inflammation and lung function over time in young adults, and the available data are somewhat limited by small sample size [7], losses to follow-up [8], and short follow-up periods [1,9]. Data from the Odense Schoolchild Study recently demonstrated that higher levels of CRP at age 20 are associated with greater reduction in $\mathrm{FEV}_{1}$ and $\mathrm{FVC}$ over nine years, but the young age of the study population makes it difficult to ascertain risk of future lung disease [10].

Extending our prior work which examined the short-term relationship between fibrinogen and lung function over 5 years [9], we explored the relationship between both GRP and fibrinogen measured in young adults aged 23 to 37 years and lung function measured over 15 years of followup in the Coronary Artery Risk Development in Young Adults (CARDIA) cohort study. We hypothesized that in young adults without lung disease, elevated 
levels of CRP and fibrinogen in young adulthood would be associated with accelerated decline in lung function over 15 years of follow-up as well as greater risk of COPD in middle age. This hypothesis, if confirmed, would imply that young adults with evidence of systemic inflammation are at increased risk for future impairments in lung health.

\section{Materials and Methods}

\section{Ethics statement}

All CARDIA exams were approved by the institutional review board at each site, and written informed consent was obtained from all subjects.

\section{Study population}

The CARDIA Study is a cohort study of 5,115 participants conducted in 4 U.S. cities [11]. The cohort has completed a total of seven examinations: year 0 (1985-1986), year 2 (1987-1988), year 5 (1990-1991), year 7 (1992-1993), year 10 (1995-1996), year 15 (2000-2001), and year 20 (2005-2006). At the time of enrollment, virtually all CARDIA participants were generally healthy and free of any overt uncontrolled chronic medical conditions [12]. 3,549 participants were examined in year 20 (a retention rate of $72 \%$ ). Participants were excluded from this analysis if they reported asthma, were on asthma medication at any of the exams, had missing or poor quality spirometry at year 20, missing CRP or fibrinogen at year 7, if pregnant at years 5, 7, or 20, or if they were transgender. The exclusions are detailed in Figure 1. The baseline characteristics of the 2,132 participants who were included in this analysis were compared to the 2,983 who either did not attend the year 20 examination or were excluded from the current analysis. Compared to those who were excluded, those included were older (25.2 vs. 24.6 years), smoked less (2.0 vs. 2.4 pack years), had lower BMI (24.2 vs. $\left.24.7 \mathrm{~kg} / \mathrm{m}^{2}\right)$, more education (14.2 vs. 13.4 years), and higher $\mathrm{FEV}_{1}(99.2 \%$ vs. $96.8 \%$ predicted), FVC (101.0\% vs. $100.0 \%$ predicted), and $\mathrm{FEV}_{1} / \mathrm{FVC}$ (83.4\% vs. $82.7 \%$ ). Excluded participants were $60 \%$ Black.

\section{Laboratory measurements}

The earliest time-point in CARDIA at which both fibrinogen and GRP were measured is year 7 . Fibrinogen was measured by a BNII nephelometer (Dade Behring, Deerfield, IL). The intra- and inter-assay coefficients of variation were 2.7 and 2.6\% [13]. CRP was measured using a BNII nephelometer (Dade Behring, Deerfield, IL), with intra- and inter-assay coefficients of variation ranging from $2.3 \%$ to $4.4 \%$, and $2.1 \%$ to $5.7 \%$ [14].

\section{Spirometry}

Spirometry was performed at all exams except years 7 and 15 . Spirometry through year 10 was measured using a Collins Survey 8-liter water sealed spirometer and an Eagle II Microprocessor (Warren E. Collins, Inc., Braintree, MA). At year 20, a dry rollingseal OMI spirometer (Viasys, Loma Linda, CA) was used. The accuracy of each spirometer was validated using the Pulmonary Waveform Generator (MH Custom Design and Manufacturing, Midvale, UT). A comparability study performed on 25 human

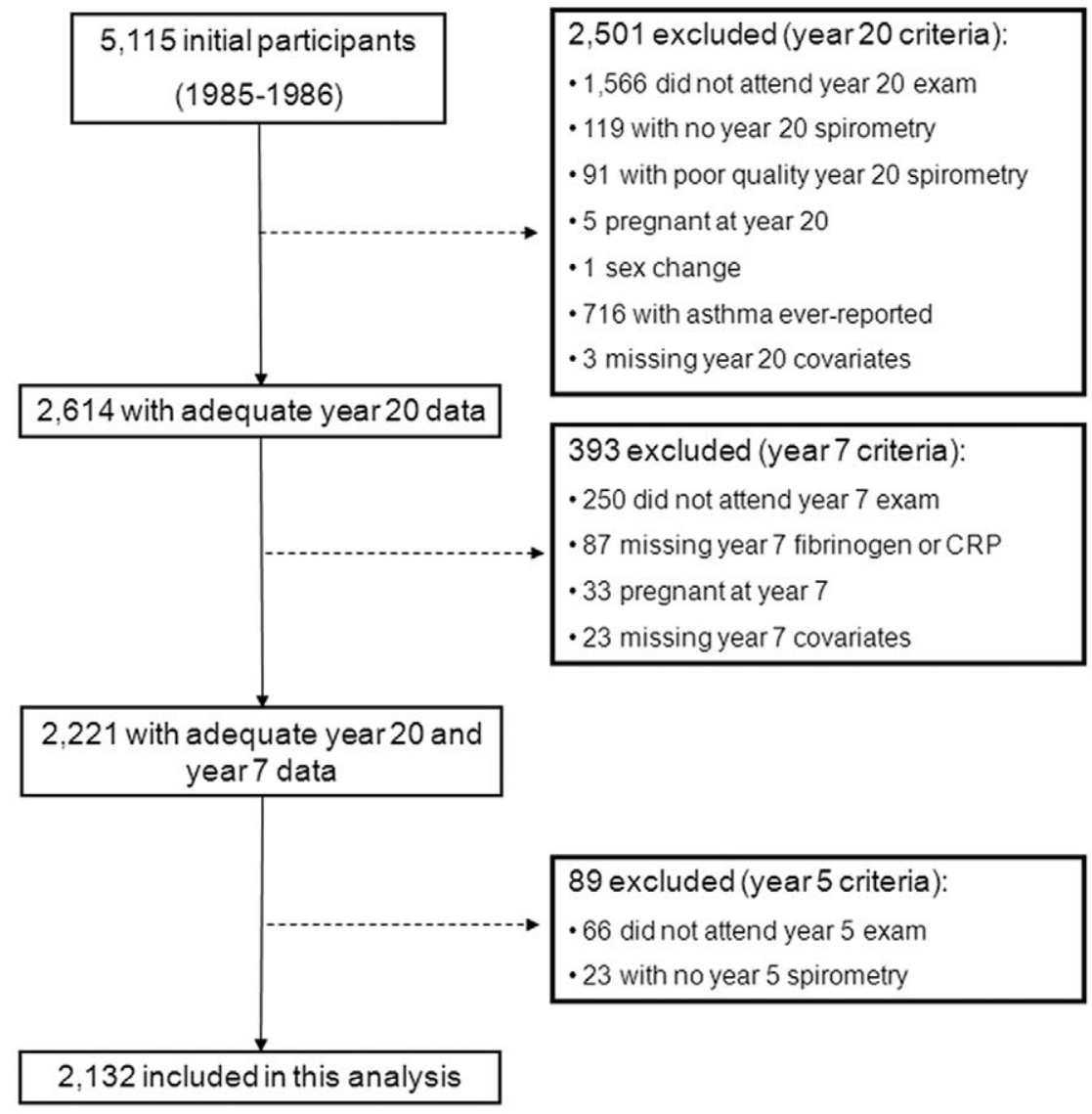

Figure 1. Summary of the population from CARDIA included in the present analysis. doi:10.1371/journal.pone.0011431.g001 
volunteers who performed forced vital capacity maneuvers on both spirometers demonstrated an average difference between the Collins and OMI spirometers of $6 \mathrm{ml}$ for forced vital capacity $\left(\mathrm{FVC}\right.$ ) and $21 \mathrm{ml}$ for (forced expiratory volume in 1 second) $\mathrm{FEV}_{1}$. Standard quality control and testing procedures were maintained according to American Thoracic Society (ATS)/European Respiratory Society (ERS) guidelines $[15,16,17,18]$.

\section{Statistical analysis}

Analysis was performed in both quartiles of fibrinogen or CRP as well as with continuous data. Because the distribution of both CRP and fibrinogen differ according to race and sex, year 7 fibrinogen and CRP levels were divided into race- and sex-specific quartiles (Table 1).

To determine whether individuals in the highest and lowest year 7 fibrinogen and CRP quartiles remained in that quartile at year 20 , we cross-tabulated the earlier and year 20 quartiles to measure the percentage of those in a given quartile at year 7 who remained in that quartile at year 20. We additionally determined the Spearman rank correlation coefficient in all participants between the earlier and year 20 time-points for both fibrinogen and CRP level.

Multivariable linear regression was used to assess the associations between fibrinogen or CRP and change in lung function from the year 5 to the year 20 examination (determined by subtracting the year $20 \mathrm{FEV}_{1}$ or FVC measurement from the year 5 measurement). Because it was not normally distributed, year 7 CRP was log transformed. Adjustment was made for race-sex group, age, age-squared, height, and height-squared at year 20 [19], BMI at the time of fibrinogen or CRP measurement, change in waist circumference from year 7 to year 20, cumulative packyears of cigarette smoking, and year 5 lung function.
Generalized estimating equations (GEE) were used to examine trends in $\mathrm{FEV}_{1}$ and FVC as a function of age over the 15 years of study. The GEE model included the following covariates: race-sex group, exam year, study center, and time-dependent age, timedependent height and height-squared, year 5 waist circumference and time-dependent change in waist circumference, time-dependent cumulative pack-years of cigarette exposure, and quartiles of fibrinogen or GRP. In one model, designed to provide a detailed visual assessment of goodness of fit to linear slope over age, age was categorized into 2-year age groups, adjusted mean lung function values were computed for each of the 14 age groups (starting with 23-24 year olds) for each quartile and plotted. In a second model, age was treated as a continuous variable and interactions between quartiles of fibrinogen or CRP and age were included to assess whether age trends for quartile 4 differed from quartile 1 .

Logistic regression was used to assess the associations of fibrinogen or CRP with year 20 spirometry values less than $80 \%$ of the predicted value according to published race- and sex-specific equations [19], COPD using the Global Initiative for Obstructive Lung Disease (GOLD) definition of $\mathrm{FEV}_{1} / \mathrm{FVC} \leq 0.70$ [20], and a non-specific spirometric abnormality defined by both $\mathrm{FEV}_{1}$ and FVC $<80 \%$ predicted with a $\mathrm{FEV}_{1} / \mathrm{FVC}>0.70$, a phenotype that is not addressed in the GOLD guidelines. Adjustment was made for study center, cigarettes smoked per day and BMI at the time of fibrinogen or CRP measurement and waist circumference and cumulative pack years of exposure to cigarettes at the time of lung function measurement. Multiplicative interactions between GRP and fibrinogen and cumulative pack years of exposure to cigarettes were also determined, and when significant ( $\mathrm{p}$ for the interaction term $<0.05)$ stratification by smoking was performed. When analyzed as a continuous variable, CRP was log

Table 1. Characteristics of the subjects included in this analysis at the time of fibrinogen and CRP (year 7) measurement. ${ }^{a}$

\begin{tabular}{|c|c|c|c|c|c|c|c|c|}
\hline \multirow[t]{2}{*}{ Characteristic } & \multicolumn{4}{|c|}{ Fibrinogen Quartile (year 7) } & \multicolumn{4}{|c|}{ CRP Quartile (year 7) } \\
\hline & 1 & 2 & 3 & 4 & 1 & 2 & 3 & 4 \\
\hline \multicolumn{9}{|l|}{$\begin{array}{l}\text { Sex- and race-specific } \\
\text { range (mean)* }\end{array}$} \\
\hline African American men & $\begin{array}{l}195-278 \\
(253)\end{array}$ & $\begin{array}{l}279-315 \\
(299)\end{array}$ & $\begin{array}{l}316-360 \\
(337)\end{array}$ & $\begin{array}{l}361-811 \\
(418)\end{array}$ & $\begin{array}{l}0.15-0.47 \\
(0.30)\end{array}$ & $\begin{array}{l}0.48-0.98 \\
(0.70)\end{array}$ & $\begin{array}{l}0.99-2.45 \\
(1.60)\end{array}$ & $\begin{array}{l}2.48-67.60 \\
(6.37)\end{array}$ \\
\hline Caucasian men & $\begin{array}{l}173-266 \\
(241)\end{array}$ & $\begin{array}{l}267-296 \\
(282)\end{array}$ & $\begin{array}{l}297-336 \\
(315)\end{array}$ & $\begin{array}{l}337-582 \\
(382)\end{array}$ & $\begin{array}{l}0.15-0.38 \\
(0.23)\end{array}$ & $\begin{array}{l}0.39-0.76 \\
(0.56)\end{array}$ & $\begin{array}{l}0.77-1.83 \\
(1.14)\end{array}$ & $\begin{array}{l}1.86-23.60 \\
(4.61)\end{array}$ \\
\hline African American women & $\begin{array}{l}107-306 \\
(270)\end{array}$ & $\begin{array}{l}307-360 \\
(335)\end{array}$ & $\begin{array}{l}361-417 \\
(387)\end{array}$ & $\begin{array}{l}418-677 \\
(479)\end{array}$ & $\begin{array}{l}0.15-0.63 \\
(0.35)\end{array}$ & $\begin{array}{l}0.64-1.77 \\
(1.12)\end{array}$ & $\begin{array}{l}1.78-4.64 \\
(3.00)\end{array}$ & $\begin{array}{l}4.65-333.00 \\
(13.52)\end{array}$ \\
\hline Caucasian women & $\begin{array}{l}136-274 \\
(244)\end{array}$ & $\begin{array}{l}275-315 \\
(295)\end{array}$ & $\begin{array}{l}316-362 \\
(338)\end{array}$ & $\begin{array}{l}363-558 \\
(417)\end{array}$ & $\begin{array}{l}0.15-0.36 \\
(0.23)\end{array}$ & $\begin{array}{l}0.37-0.93 \\
(0.61)\end{array}$ & $\begin{array}{l}0.95-2.41 \\
(1.55)\end{array}$ & $\begin{array}{l}2.43-60.50 \\
(6.88)\end{array}$ \\
\hline Mean age in years (SD) & $31.9(3.5)$ & $32.1(3.7)$ & $32.3(3.5)$ & $32.4(3.5)$ & $32.2(3.6)$ & $32.1(3.5)$ & $32.3(3.5)$ & $32.2(3.6)$ \\
\hline Female gender & $54 \%$ & $54 \%$ & $54 \%$ & $54 \%$ & $54 \%$ & $54 \%$ & $54 \%$ & $54 \%$ \\
\hline \multicolumn{9}{|l|}{ Race } \\
\hline African-American & $40 \%$ & $41 \%$ & $40 \%$ & $40 \%$ & $40 \%$ & $41 \%$ & $40 \%$ & $40 \%$ \\
\hline Caucasian & $60 \%$ & $59 \%$ & $60 \%$ & $60 \%$ & $60 \%$ & $59 \%$ & $60 \%$ & $60 \%$ \\
\hline \multicolumn{9}{|l|}{ Education level } \\
\hline High school or less & $22 \%$ & $23 \%$ & $24 \%$ & $26 \%$ & $21 \%$ & $24 \%$ & $23 \%$ & $26 \%$ \\
\hline More than high school & $78 \%$ & $77 \%$ & $76 \%$ & $74 \%$ & $79 \%$ & $76 \%$ & $77 \%$ & $74 \%$ \\
\hline Ever-smoker & $45 \%$ & $45 \%$ & $45 \%$ & $47 \%$ & $41 \%$ & $45 \%$ & $50 \%$ & $45 \%$ \\
\hline $\begin{array}{l}\text { Body mass index } \\
\left(\mathrm{kg} / \mathrm{m}^{2}\right)(\mathrm{SD})\end{array}$ & $24.0(3.7)$ & $25.2(4.4)$ & $26.4(4.9)$ & $29.6(7.0)$ & $23.4(3.4)$ & $25.4(4.0)$ & $26.7(5.0)$ & $29.7(7.0)$ \\
\hline
\end{tabular}

${ }^{a}$ Fibrinogen expressed in $\mathrm{mg} / \mathrm{dL}, \mathrm{CRP}$ expressed in $\mu \mathrm{g} / \mathrm{mL}$.

doi:10.1371/journal.pone.0011431.t001 
Table 2. Spearman rank correlation coefficients between year 7 and year 20 fibrinogen and CRP measurements.

\begin{tabular}{|c|c|c|c|}
\hline Gender & $\begin{array}{l}\text { Spearman rank } \\
\text { correlation } \\
\text { coefficient* }^{*}\end{array}$ & $\begin{array}{l}\%(95 \% \mathrm{Cl}) \text { in } \\
\text { quartile } 1 \text { at } \\
\text { year } 7 \text { also in } \\
\text { quartile } 1 \text { at } \\
\text { year } 20\end{array}$ & $\begin{array}{l}\%(95 \% \mathrm{Cl}) \text { in } \\
\text { quartile } 4 \text { at } \\
\text { year } 7 \text { also in } \\
\text { quartile } 4 \text { at } \\
\text { year } 20\end{array}$ \\
\hline \multicolumn{4}{|l|}{ CRP } \\
\hline Male & 0.56 & $54(48,61)$ & $51(45,58)$ \\
\hline Female & 0.56 & $55(49,61)$ & $53(47,50)$ \\
\hline \multicolumn{4}{|c|}{ Fibrinogen } \\
\hline Male & 0.51 & $53(46,59)$ & $49(42,55)$ \\
\hline Female & 0.57 & $51(45,57)$ & $54(48,60)$ \\
\hline
\end{tabular}

transformed to better achieve the requirement that the logit be linear in its parameters.

All statistical analyses were conducted using SAS for Windows, release 9.2 (SAS Institute Inc., Cary, NG).

\section{Results}

\section{Subject characteristics}

The plasma levels for the race- and sex-specific year 7 fibrinogen and CRP quartiles and demographic characteristics of the study population are included in Table 1. As expected, ever smoking and higher BMI were associated with higher fibrinogen and CRP. Because fibrinogen and CRP are both acute phase reactants, we assessed whether individuals with high fibrinogen or CRP at year 7 continued to have high levels at year 20. The majority of participants in the highest and lowest quartiles of fibrinogen or CRP at year 7 remained in that quartile at year 20 (Table 2).

\section{Systemic inflammation in young adults and change in} lung function over 15 years

Higher year 7 fibrinogen as well as CRP were associated with greater 15 year decline in both $\mathrm{FVC}$ and $\mathrm{FEV}_{1}$. (Table 3).
Models of lung function with age and the interaction with fibrinogen and CRP

The interaction between systemic inflammation in young adults and age-related decline in lung function was assessed using spirometry values from exam years 5, 10, and 20 in a GEE model. For both year 7 fibrinogen and CRP, quartile 4 had a greater agerelated decline in FVC compared with quartile 1 ( $\mathrm{P}$ value for the age-fibrinogen quartile or age-CRP quartile interaction on decline in lung function $<0.001$ ). In contrast, there was no significant interaction between age-related decline in $\mathrm{FEV}_{1}$ and fibrinogen or CRP (Figure 2).

\section{Systemic inflammation in young adults and abnormal lung function 13-15 years later}

Year 7 fibrinogen was associated with abnormal year $20 \mathrm{FVC}$ and $\mathrm{FEV}_{1}$, as well as the non-specific abnormality at year 20, but not COPD (Table 4). Year 7 CRP was associated with abnormal year $20 \mathrm{FVC}$, but not $\mathrm{FEV}_{1}$, the non-specific abnormality, or COPD (Table 4). We did not observe an interaction between fibrinogen and pack-years cigarette smoking on any outcomes. A positive interaction was observed between CRP and pack-years cigarette smoking on the COPD endpoint (but no other endpoints related to $\mathrm{CRP}$ ) prompting subsequent analysis of the association between year 7 CRP and COPD stratified by smoking. Among participants with 10 or more pack years of cigarette smoking, higher year 7 CRP was associated with greater odds of COPD at year 20 (Table 5).

To evaluate the effects of systemic inflammation independent of baseline lung function, we repeated this analysis excluding individuals with abnormal lung function at year 5: 87 participants had abnormal year $5 \mathrm{FEV}_{1}, 53$ had abnormal year $5 \mathrm{FVC}, 52$ had COPD at year 5 , and 40 had the non-specific abnormality at year 5 and were therefore excluded. The association between year 7 fibrinogen and year $20 \mathrm{FEV}_{1}<80 \%$ predicted was preserved (odds ratio $(\mathrm{OR})$ per standard deviation fibrinogen $1.38(95 \%$ confidence interval (CI): $1.17-1.63 ; P<0.001)$ as was the association with year $20 \mathrm{FVC}<80 \%$ predicted (OR per standard deviation fibrinogen 1.55 (95\% CI: $1.31-1.83, P<0.001)$ and the non-specific spirometry abnormality at year 20 (OR per standard deviation fibrinogen 1.50 (95\% CI: $1.16-1.70 ; P<0.001)$. In addition, the association year $7 \mathrm{CRP}$ with $\mathrm{FVC}<80 \%$ predicted at year 20 remained significant (OR per standard deviation logtransformed CRP 1.33 (95\% CI: $1.11-1.59 ; \quad P=0.002)$. The

Table 3. Adjusted loss of FVC and FEV from year 5 to year 20 across race-sex specific quartiles of year 7 fibrinogen and CRP as well as linear regression coefficients for fibrinogen and log-transformed CRP as continuous variables.

\begin{tabular}{|c|c|c|c|c|c|c|}
\hline \multirow{2}{*}{$\frac{\text { Loss of Lung Function }}{\text { (Year } 5 \text { minus Year 20) }}$} & \multicolumn{4}{|c|}{ Fibrinogen Quartile (Year 7) } & \multirow[b]{2}{*}{ Beta $^{\dagger}$} & \multirow[b]{2}{*}{$P$} \\
\hline & 1 & 2 & 3 & 4 & & \\
\hline $\mathrm{FEV}_{1}(\mathrm{~mL})$ & 446 & 456 & 464 & 487 & 0.333 & $<0.001$ \\
\hline \multirow[t]{3}{*}{$\mathrm{FVC}(\mathrm{mL})$} & 398 & 14 & 441 & 439 & 0.418 & $<0.001$ \\
\hline & \multicolumn{4}{|c|}{ CRP Quartile (Year 7) } & & \\
\hline & 1 & 2 & 3 & 4 & Beta $^{\dagger}$ & $P$ \\
\hline $\mathrm{FEV}_{1}(\mathrm{~mL})$ & 442 & 453 & 468 & 491 & 16.383 & 0.001 \\
\hline FVC (mL) & 390 & 422 & 425 & 455 & 19.199 & $<0.001$ \\
\hline
\end{tabular}


Fibrinogen
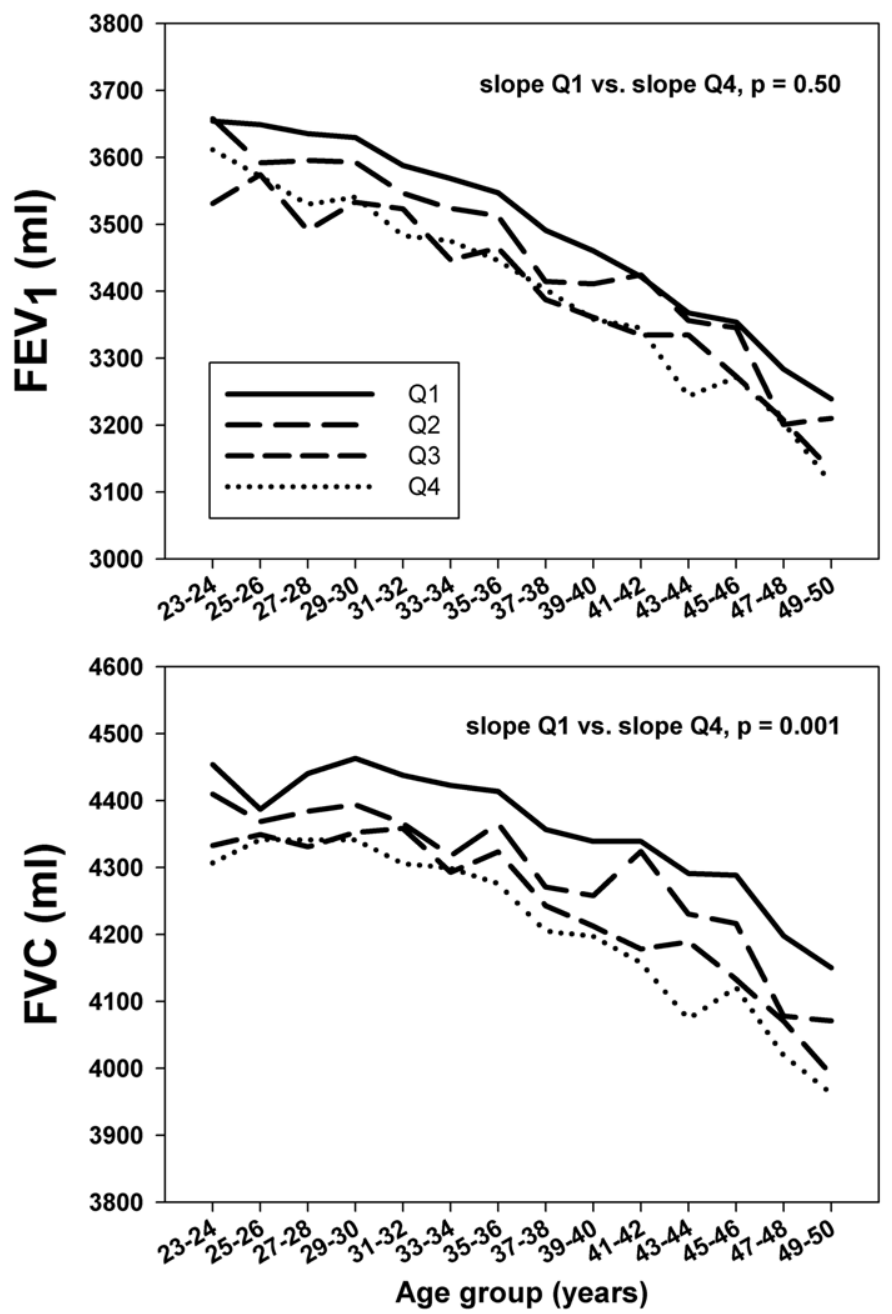

C-reactive protein
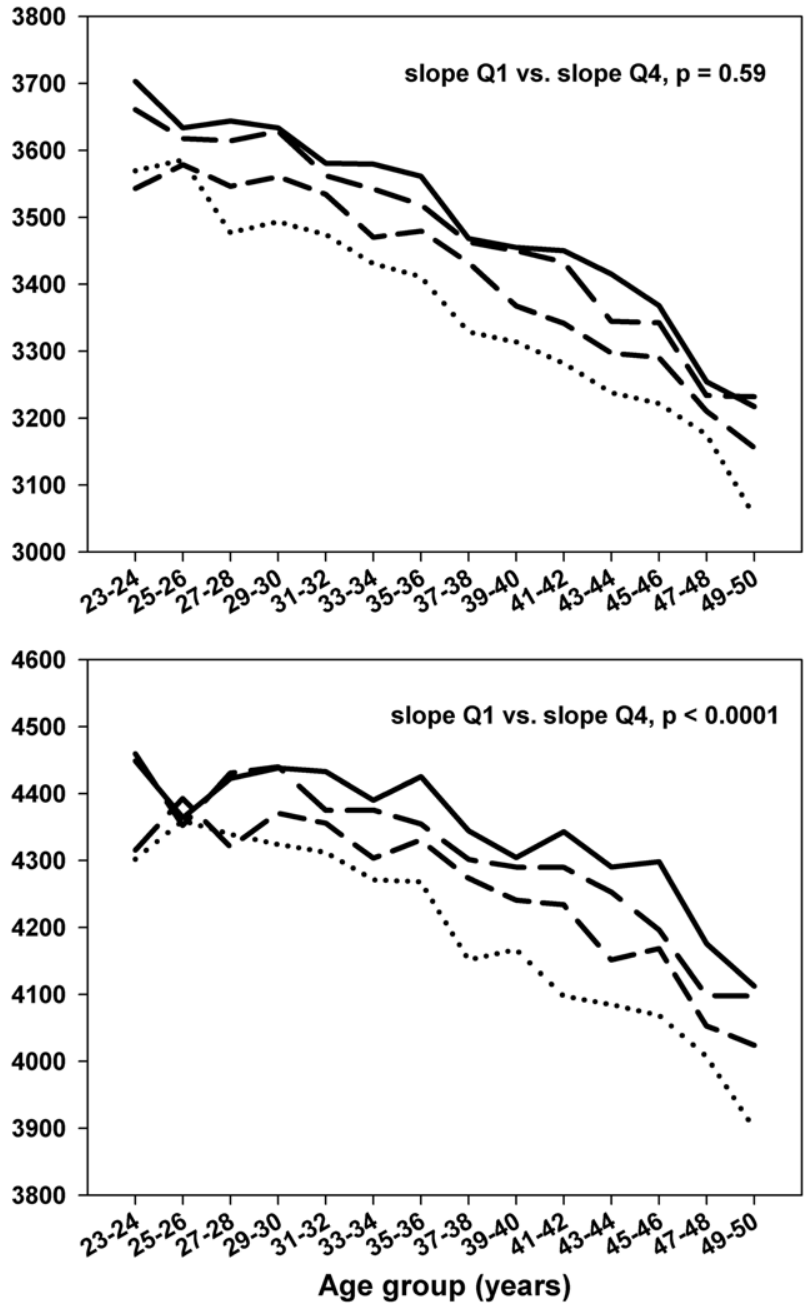

Figure 2. Relationship between age, lung function and quartile of fibrinogen or CRP (measured at year 7). Spirometry exams performed at CARDIA visits at years 5, 10, and 20 were used to determine a mean lung function for each 2 year age group across year 7 CRP or fibrinogen quartiles, and slopes compared between the highest and lowest quartile groups. For both fibrinogen and CRP, the age-related decline in

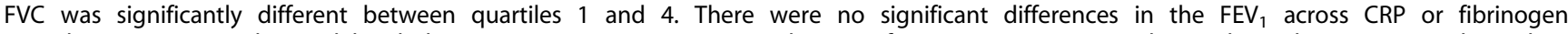
quartiles.Covariates in the model include race-sex group, exam year, pack-years of cigarette exposure, and time-dependent age, time-dependent height and height-squared, and year 5 waist circumference and time-dependent change in waist circumference.

doi:10.1371/journal.pone.0011431.g002

positive interaction between pack-years of cigarette exposure and CRP on the COPD endpoint remained significant $(P$ for the log transformed CRP x pack-years exposure interaction $=0.04)$. We also repeated the analysis of CRP and COPD stratified by smoking excluding those with COPD at baseline. While no longer statistically significant, the trend for the association between CRP and COPD remained among participants with 10 or more pack-years (OR per standard deviation log transformed CRP 1.36 (95\% CI: $0.91,2.03, P=0.14)$ ).

\section{Discussion}

We report three major findings. First, greater systemic inflammation in young adults is associated with greater decline in lung function over 15 years as well as having abnormal lung function 13 years later. Participants in the highest year 7 fibrinogen or CRP quartiles had greater $\mathrm{FEV}_{1}$ and FVC decline compared to those with the lowest quartiles over 15 years of follow-up. Second, higher levels of year 7 fibrinogen and CRP in young adulthood are associated with greater risk of having an abnormal FVG (fibrinogen and CRP) and $\mathrm{FEV}_{1}$ (fibrinogen) in middle-age. Third, among participants who smoked 10 or more pack-years of cigarettes, year 7 CRP is associated with increased risk of having obstructive lung disease at year 20.

Cross-sectional studies have documented that increased systemic inflammation is associated with lower lung function in both healthy adults and patients with COPD [1,2,3,21]. In older populations, there appears to be an association between systemic inflammation and risk of COPD. In a Dutch study of subjects 55 years of age and older, CRP was associated with increased risk of incident COPD [6], and in a study of 5,247 healthy Swedish men of mean age 46 years, a panel of inflammation sensitive plasma proteins including CRP was associated with increased risk of COPD hospitalization [5]. There are, however, limited and 
Table 4. Adjusted odds ratios $(95 \% \mathrm{Cl})$ for $\mathrm{FEV}_{1}$ or $\mathrm{FVC}$ less than $80 \%$ predicted, COPD using the GOLD definition (FEV $\left.1 / \mathrm{FVC} \leq 0.70\right)$ or a non-specific spirometry abnormality (FEV $1_{1}$ and FVC $<80 \%$ with $\mathrm{FEV}_{1} / \mathrm{FVC}>0.70$ ) at year 20 across race- and sex-specific quartiles of year 7 fibrinogen and CRP and per standard deviation of fibrinogen or log-transformed CRP.*

\begin{tabular}{|c|c|c|c|c|c|c|c|}
\hline \multirow{2}{*}{$\frac{\text { Spirometry }}{\text { (year 20) }}$} & \multicolumn{5}{|c|}{ Year 7 Fibrinogen Quartile } & \multirow{2}{*}{$\frac{\text { Per SD }}{(\mathrm{mg} / \mathrm{dL})}$} & \multirow[b]{2}{*}{$P$} \\
\hline & $\mathbf{N}$ & 1 & 2 & 3 & 4 & & \\
\hline $\mathrm{FEV}_{1}<80 \%$ & 241 & 1.0 & $1.11(0.71,1.73)$ & $1.49(0.98,2.26)$ & $1.23(0.79,1.91)$ & $1.37(1.19,1.59)$ & $<0.001$ \\
\hline $\mathrm{FVC}<80 \%$ & 214 & 1.0 & $1.27(0.77,2.09)$ & $2.02(1.28,3.21)$ & $1.77(1.09,2.87)$ & $1.51(1.30,1.75)$ & $<0.001$ \\
\hline COPD (GOLD) & 126 & 1.0 & $0.72(0.42,1.22)$ & $1.00(0.61,1.65)$ & $0.87(0.50,1.51)$ & $0.93(0.75,1.16)$ & 0.51 \\
\hline \multirow[t]{3}{*}{ Non-specific abnormality } & 149 & 1.0 & $1.10(0.62,1.97)$ & $1.78(1.05,3.01)$ & $1.27(0.77,2.23)$ & $1.47(1.19,1.68)$ & $<0.001$ \\
\hline & \multicolumn{5}{|c|}{ Year 7 CRP Quartile } & Per SD ${ }^{\dagger}$ & \\
\hline & $\mathbf{N}$ & 1 & 2 & 3 & 4 & $(\mu \mathrm{g} / \mathrm{mL})$ & $P$ \\
\hline $\mathrm{FEV}_{1}<80 \%$ & 241 & 1.0 & $0.79(0.51,1.22)$ & $0.94(0.62,1.43)$ & $0.98(0.63,1.51)$ & $1.17(1.00,1.37)$ & 0.05 \\
\hline FVC $<80 \%$ & 214 & 1.0 & $0.89(0.55,1.44)$ & $1.26(0.80,1.99)$ & $1.36(0.85,2.17)$ & $1.35(1.14,1.59)$ & $<0.001$ \\
\hline COPD (GOLD) & 126 & 1.0 & $0.94(0.56,1.57)$ & $0.90(0.53,1.54)$ & $1.13(0.66,1.96)$ & $0.98^{*}(0.80,1.21)$ & 0.86 \\
\hline Non-specific abnormality & 149 & 1.0 & $0.70(0.41,1.20)$ & $0.82(0.49,1.39)$ & $0.81(0.47,1.40)$ & $1.14(0.94,1.39)$ & 0.18 \\
\hline
\end{tabular}

*Adjusted for center, cigarettes/d, BMI at the time of fibrinogen and CRP measurement, and waist circumference and cumulative pack-years of cigarette exposure at the time of spirometry.

${ }^{\dagger}$ Adjusted odds ratio per standard deviation of year 7 fibrinogen or log-transformed CRP.

Test for CRP x pack-years cigarette exposure interaction significant $(P=0.005)$. doi:10.1371/journal.pone.0011431.t004

conflicting reports of the association between systemic inflammation and lung function change over time in young adults. Fogarty, et al found no association between baseline CRP and decline in lung function over nine years in 2,442 individuals aged $18-70$ years [8]. Among 531 participants 20 to 44 years of age in the European Community Respiratory Health Survey, increases in CRP over an 8 year period were associated with greater annual declines in $\mathrm{FEV}_{1}$, although there was no significant association between baseline CRP and annual decline in $\mathrm{FEV}_{1}$ [7]. We performed a previous analysis from CARDIA that found that participants in the highest quartile of fibrinogen at year 5 of the study had year $10 \mathrm{FEV}_{1}$ and FVC values that were $45 \mathrm{ml}$ and $67 \mathrm{ml}$ lower than those in the lowest quartile [9]. We now extend upon this prior work to document that both fibrinogen and CRP in young adults are associated with accelerated decline in lung function as well as abnormal lung function over 15 years of followup.

The origins of elevated markers of systemic inflammation in the CARDIA cohort are uncertain. One can speculate that early lung inflammation resulting from environmental exposures beyond cigarette smoking results in decreasing lung function over time.
These exposures could also be accompanied by increased levels of plasma fibrinogen and CRP as the systemic response to the primary locus of inflammation in the lung. Both cigarette smoke and ambient particulate matter have a high burden of oxidant molecules. When inhaled, these likely result in significant local oxidant stress in the lung resulting in local increases in proinflammatory gene expression [22]. Ambient particulate matter has been shown to stimulate release of TNF- $\alpha$ as well as other cytolines including granulocyte macrophage colony-stimulated factor (GM-CSF), interleukin (IL)- 6 and IL- $1 \beta$ by human alveolar macrophages [23]. These cytokines may then "spill-over" into the systemic circulation where they induce production of acute phase reactants such as fibrinogen and CRP. The absence of samples collected directly from the lungs of CARDIA participants which could then be correlated with CRP and fibrinogen in the blood limits our ability to explore this possibility further in the CARDIA cohort.

Alternatively, some individuals may have genetic variation that results in high systemic inflammation which results in increased risk of adverse health outcomes if they have the additional exposure of cigarette smoking $[24,25]$. These individuals may have

Table 5. Adjusted odds ratios $(95 \% \mathrm{Cl})$ for COPD using the GOLD definition (FEV $1 / F V C \leq 0.70)$ at year 20 across race- and sexspecific quartiles of year 7 CRP and per standard deviation of CRP stratified by pack-years cigarette exposure.

\begin{tabular}{|c|c|c|c|c|c|c|c|}
\hline \multirow{2}{*}{$\begin{array}{l}\text { Pack-Years } \\
\text { Smoking }\end{array}$} & \multicolumn{5}{|c|}{ Year 7 CRP Quartile } & \multirow{2}{*}{$\frac{\text { Per SD }}{(\mu \mathrm{g} / \mathrm{mL})}$} & \multirow[b]{2}{*}{$P$} \\
\hline & $\mathbf{N}^{\star}$ & 1 & 2 & 3 & 4 & & \\
\hline 0 pack-years $(N=1249)$ & 53 & 1.0 & $0.66(0.32,1.38)$ & $0.48(0.21,1.12)$ & $0.72(0.32,1.60)$ & $0.77(0.55,1.06)$ & 0.11 \\
\hline 1-9 pack-years $(\mathrm{N}=501)$ & 26 & 1.0 & $1.11(0.43,2.88)$ & $0.29(0.06,1.42)$ & $0.95(0.26,3.52)$ & $0.78(0.46,1.32)$ & 0.35 \\
\hline $10+$ pack-years $(\mathrm{N}=382)$ & 47 & 1.0 & $2.46(0.60,10.11)$ & $5.01(1.38,18.22)$ & $4.90(1.29,18.59)$ & $1.53(1.08,2.16)$ & 0.02 \\
\hline
\end{tabular}

*Adjusted for center, cigarettes/day, and BMI at the time of CRP measurement, and waist circumference and cumulative pack-years of cigarette exposure at the time of spirometry.

†Adjusted odds ratio for COPD per standard deviation of log-transformed year 7 CRP.

Number of year 20 COPD cases in each smoking stratum.

doi:10.1371/journal.pone.0011431.t005 
an "inflammatory phenotype" characterized by concurrent exaggerated inflammatory responses in both the lung and systemic compartments. We observed that among participants at the highest risk for developing COPD (10 or more pack-years of smoking cigarettes), those with higher CRP in young adulthood had elevated risk of COPD in middle age. This indicates that smoking in a vulnerable population (those with high GRP) might confer an accelerated risk of obstructive lung disease, compared to the elevated inflammatory marker alone. Regardless of whether CRP elevation is the result of "spill-over" or reflective of an "inflammatory phenotype", it may be valuable as a marker to identify those cigarette smokers who are at greatest risk of developing COPD in the future.

In our study, CRP and fibrinogen were not consistently associated with the same patterns of lung function change over time. We found that year 7 fibrinogen and CRP were both associated with low FVC at year 20, but fibrinogen was also associated with abnormal $\mathrm{FEV}_{1}$ and the non-specific reduction in both $\mathrm{FEV}_{1}$ and $\mathrm{FVC}$ with a preserved $\mathrm{FEV}_{1} / \mathrm{FVC}$. In addition, while there was an interaction between CRP and cigarette smoking, fibrinogen was not associated with COPD and did not interact with smoking. Fibrinogen, therefore, may be a marker of individuals at risk for restrictive lung disease. Alternatively, in non-smokers, high fibrinogen and CRP may mark risk for accelerated age-related decline in lung function, without the development of any specific lung disease. Both patterns and their respective blood markers are of considerable interest since reductions in both $\mathrm{FEV}_{1}$ and $\mathrm{FVC}$ in the absence of a diagnosis of lung disease are associated with cardiovascular and metabolic disease [3,26].

It has recently been advocated that COPD be incorporated into the "chronic systemic inflammatory syndrome" [27]. This syndrome-based approach relies on the concept that chronic systemic inflammation underlies not only COPD, but also other co-morbid conditions, including cardiovascular disease and the metabolic syndrome [27]. Our data indicate that systemic inflammation in young adults, particularly CRP in cigarette smokers, is associated with future impairment in lung health, prompting the hypothesis that the systemic inflammation that links COPD with various co-morbidities may be detectable prior to the onset of clinically overt disease.

The major strength of our study is the long-term followup of a cohort with serial lung function measurements. In addition, the age of the cohort at the year 20 examination allows us to begin to evaluate whether accelerated decline in lung function that occurs in association with high levels of systemic inflammation in young adults which has been reported by others [10], and confirmed in our present report, actually results in clinical disease. We document that in the highest risk group (those with 10 or greater pack years of cigarette smoking) GRP in young adults is associated with the presence of COPD 13 years later.

We note some limitations in our study. CRP and fibrinogen measurements were not measured at the baseline visit. However, the relatively early measurement of fibrinogen and CRP (year 7) compared to lung function measurement (year 20) ensures that the exposure of systemic inflammation predated, by more than a decade, our principle outcome measurements. While both fibrinogen and CRP are acute phase reactants and the duration of exposure can be called into question, we documented that those in the highest and lowest quartiles at the early time point of measurement tend to remain in those categories at later time points. The absence of specimens that directly measure lung inflammation in the cohort limits our ability to link the inflammatory responses in the systemic and respiratory compartments. Another limitation is the absence of post-bronchodilator spirometry testing as well as a lack of information about static lung volumes or lung imaging, which would provide insights into the structural changes in the lungs of participants observed to have physiologic abnormalities. In addition, although we have adjusted for waist circumference at the time of lung function measurement and BMI at the time of fibrinogen and CRP measurement in all statistical models, our analysis remains vulnerable to residual confounding due to possible associations between obesity, lung function, and inflammation. Since both increased levels of CRP and fibrinogen were associated at baseline with increased BMI, the possibility that obesity plays a critical role in the lung function-systemic inflammation relationship remains a clear possibility. Indeed, obesity is associated with high CRP and fibrinogen [28] and lower lung function [29] and may provide another link between systemic inflammation and low lung function.

In conclusion, among a generally healthy population of young adults, higher levels of plasma fibrinogen and CRP are associated with accelerated decline in lung function. In individuals who smoke more than 10 pack-years of cigarettes, higher levels of CRP during young adulthood are associated with greater risk of COPD in middle age. These findings indicate that individuals with increased systemic inflammation early in life may be at increased risk for future impairments in lung health, and CRP, in particular, may be a useful marker of vulnerability for COPD among cigarette smokers.

\section{Author Contributions}

Conceived and designed the experiments: RK BTT LAC SRR KL BT DRJJ LJS. Performed the experiments: KL DRJJ. Analyzed the data: RK BTT LAC SRR KL BT DRJJ LJS. Contributed reagents/materials/ analysis tools: KL. Wrote the paper: RK BTT LAC SRR KL BT DRJJ LJS.

\section{References}

1. Hancox RJ, Poulton R, Greene JM, Filsell S, McLachlan CR, et al. (2007) Systemic inflammation and lung function in young adults. Thorax 62: 1064-1068.

2. Aronson D, Roterman I, Yigla M, Kerner A, Avizohar O, et al. (2006) Inverse Association between Pulmonary Function and C-Reactive Protein in Apparently Healthy Subjects. Am J Respir Crit Care Med 174: 626-632.

3. Mannino DM, Ford ES, Redd SC (2003) Obstructive and restrictive lung disease and markers of inflammation: data from the Third National Health and Nutrition Examination. Am J Med 114: 758-762.

4. Walter RE, Wilk JB, Larson MG, Vasan RS, Keaney JF, Jr., et al. (2008) Systemic Inflammation and COPD: The Framingham Heart Study. Chest 133: 19-25.

5. Engstrom G, Segelstorm N, Ekberg-Aronsson M, Nilsson PM, Lindgarde F, et al. (2009) Plasma markers of inflammation and incidence of hospitalisations for COPD: results from a population-based cohort study. Thorax 64: 211215
6. van Durme YMTA, Verhamme KMC, Aarnoudse A-JLHJ, Van Pottelberge GR, Hofman A, et al. (2009) C-Reactive Protein Levels, Haplotypes, and the Risk of Incident Chronic Obstructive Pulmonary Disease. Am J Respir Crit Care Med 179: 375-382.

7. Shaaban R, Kony S, Driss F, Leynaert B, Soussan D, et al. (2006) Change in Creactive protein levels and FEV1 decline: a longitudinal population-based study. Respir Med 100: 2112-2120.

8. Fogarty AW, Jones S, Britton JR, Lewis SA, McKeever TM (2007) Systemic inflammation and decline in lung function in a general population: a prospective study. Thorax 62: 515-520.

9. Thyagarajan B, Jacobs DR, Apostol GG, Smith LJ, Lewis CE, et al. (2006) Plasma fibrinogen and lung function: the CARDIA Study. Int J Epidemiol 35: 1001-1008.

10. Rasmussen F, Mikkelsen D, Hancox RJ, Lambrechtsen J, Nybo M, et al. (2009) High-sensitive G-reactive protein is associated with reduced lung function in young adults. Eur Respir J 33: 382-388. 
11. Hughes GH, Gutter G, Donahue R, Friedman GD, Hulley S, et al. (1987) Recruitment in the Coronary Artery Disease Risk Development in Young Adults (CARDIA) Study. Control Clin Trials 8: 68S-73S.

12. Friedman GD, Cutter GR, Donahue RP, Hughes GH, Hulley SB, et al. (1988) CARDIA: study design, recruitment, and some characteristics of the examined subjects. J Clin Epidemiol 41: 1105-1116.

13. Reiner AP, Carty CL, Carlson CS, Wan JY, Rieder MJ, et al. (2006) Association between patterns of nucleotide variation across the three fibrinogen genes and plasma fibrinogen levels: the Coronary Artery Risk Development in Young Adults (CARDIA) study. J Thromb Haemost 4: 1279-1287.

14. Lakoski SG, Herrington DM, Siscovick DM, Hulley SB (2006) C-reactive protein concentration and incident hypertension in young adults: the CARDIA study. Arch Intern Med 166: 345-349.

15. American Thoracic Society (1979) Snowbird workshop on standardization of spirometry. Am Rev Respir Dis 119: 831-838.

16. American Thoracic Society (1987) Standardization of spirometry-1987 update. Am Rev Respir Dis 136: 1285-1298.

17. American Thoracic Society (1995) Standardization of Spirometry, 1994 Update. Am J Respir Crit Care Med 152: 1107-1136.

18. Miller MR, Hankinson J, Brusasco V, Burgos F, Casaburi R, et al. (2005) Standardisation of spirometry. Eur Respir J 26: 319-338.

19. Hankinson JL, Odencrantz JR, Fedan KB (1999) Spirometric reference values from a sample of the general U.S. population. Am J Respir Crit Care Med 159: 179-187.

20. Rabe KF, Hurd S, Anzueto A, Barnes PJ, Buist SA, et al. (2007) Global strategy for the diagnosis, management, and prevention of chronic obstructive pulmonary disease: GOLD executive summary. Am J Respir Crit Care Med 176: 532-555.

21. Pinto-Plata VM, Mullerova H, Toso JF, Feudjo-Tepie M, Soriano JB, et al. (2006) C-reactive protein in patients with COPD, control smokers and nonsmokers. Thorax 61: 23-28.

22. MacNee W (2005) Pulmonary and systemic oxidant/antioxidant imbalance in chronic obstructive pulmonary disease. Proc Am Thorac Soc 2: 50-60.

23. van Eeden SF, Tan WC, Suwa T, Mukae H, Terashima T, et al. (2001) Cytokines involved in the systemic inflammatory response induced by exposure to particulate matter air pollutants $(\mathrm{PM}(10))$. Am J Respir Crit Care Med 164: 826-830.

24. Pankow JS, Folsom AR, Cushman M, Borecki IB, Hopkins PN, et al. (2001) Familial and genetic determinants of systemic markers of inflammation: the NHLBI family heart study. Atherosclerosis 154: 681-689.

25. Sunyer J, Pistelli R, Plana E, Andreani M, Baldari F, et al. (2008) Systemic inflammation, genetic susceptibility and lung function. Eur Respir J 32: 92-97.

26. Mannino DM, Thorn D, Swensen A, Holguin F (2008) Prevalence and outcomes of diabetes, hypertension and cardiovascular disease in COPD. Eur Respir J 32: 962-969.

27. Fabbri LM, Rabe KF (2007) From COPD to chronic systemic inflammatory syndrome? Lancet 370: 797-799.

28. Haffner SM (2007) Abdominal Adiposity and Cardiometabolic Risk: Do We Have All the Answers? Am J Med 120: S10-S16.

29. Rossi A, Fantin F, Di Francesco V, Guariento S, Giuliano K, et al. (2008) Body composition and pulmonary function in the elderly: a 7-year longitudinal study. Int J Obes 32: 1423-1430. 